\title{
Materials Research is Big Science
}

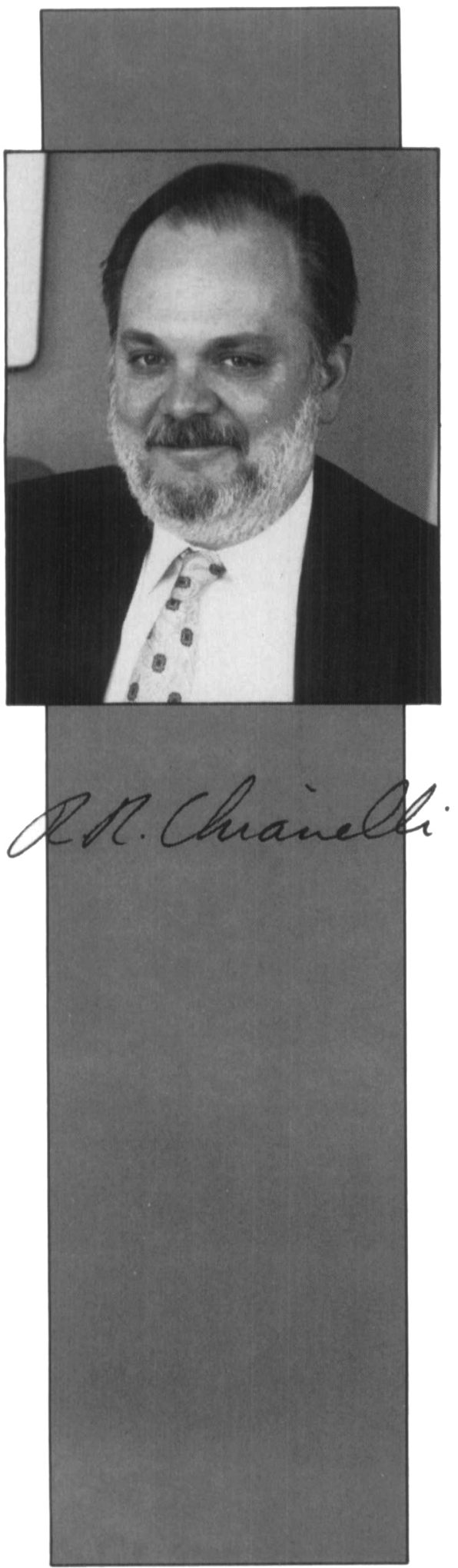

We are all well aware of the "Big Science" projects now being undertaken in the United States and the "big price tags" attached to them. Projects such as the Superconducting Super Collider (SSC), the orbiting space station and elucidation of the human genome capture the imagination of congressional leaders and the general public, generating wide support. This support arises from the still strong belief that science will provide an endless stream of exciting discoveries leading to insight into the nature of our physical universe and ultimately to a better life for all.

MRS members, with a large store of curiosity which drove them to be scientists in the first place, as a group are probably even more enthusiastic than the average public about these projects. And perhaps we believe as individuals that these projects will benefit our own research programs with numerous new materials problems that will yield to our efforts, given enough time and a "slice of the forthcoming funding pie." This may indeed be true as funding in these areas expand to take up some of the slack created by the looming cutbacks in defense-oriented research. I for one also believe that it is important for our "national phsyche" to pursue these projects.

But there are others who express concern that these "Big Science" projects will take too much from the "Small Science" programs most familiar to the MRS community. Foremost in this group is Rustum Roy, former MRS Councillor and President, who outspokenly presents evidence that large projects are already diverting funds from many materials science efforts in the current highly competitive funding environment. One need only talk to our academic friends to realize that funding in materials science has taken a turn for the worse and that "Big Science" is certainly a factor.

However, I believe that another factor is coming into play and that is the apparent inability of materials scientists to effectively make the case for funding of materials science as "Big Science." Funding for materials science, or what falls under the umbrella of materials science, is already a huge item in the federal budget, approximately $\$ 1.1$ billion. But the appropriation of this money is highly fragmented, and the potential impact of the research being funded is virtually unknown to the public. Materials scientists - as individuals and a community - need to learn how to present their case for research funding more effectively, making clear to the public the value of investing in materials research.

Materials scientists-as
individuals and a
community - need to
learn how to present
their case for research
funding more effec-
tively, making clear to
the public the value of
investing in materials
research.

That we have not done this is surprising to me because it seems that the case for funding materials science is as strong maybe stronger - than the argument for funding the array of classic "Big Science" projects. These projects promise future benefits to mankind often in very hazy terms, with the promise being something like "trust us something will come of it," or nothing but knowledge of ourselves, our universe or God himself. On the other hand, materials scientists can powerfully argue that the quality of life in this decade and far into the 21st century will depend on the effectiveness of materials research and its impact on the competitiveness of our economy (and thus our standard of living) and the quality of our environment. Any materials scientist can paint a picture of daily life in the 21st century dominated by new materials that will have changed the way we live today. The importance of materials science to our general well-being and everyday quality of life should be obvious to all. But it seems that this is not so, as reflected by the "ho-hum" response to discussions of materials science or its research funding.

It is my belief that what is needed for materials science is better packaging. This means assembling areas of materials science into large "banner projects" that clearly have large public impact and capture the public's imagination. Such an approach was recently suggested at a 
meeting of the Northeast Regional MS\&E Steering Committee.

An example of a potential materials banner project, which I have recently written about, is revitalizing our transportation system with a "National Magnetic Levitation Transportation Project." The impact of such a project on the national economy and on materials research would be enormous. We could set a national goal of having by, say, the year 2010 the most advanced Maglev transportation system in the world with $350 \mathrm{mph}$ capability. Just setting such a national goal would have great impact on national morale and confidence.

And, a national Maglev project would have payoff beyond this. A recent Department of Transportation study (reported by the New York Times) estimates that by the year 2005 traffic jams will waste 12 billion working hours a year and airport delays will cost passengers $\$ 13$ billion. Carnegie Mellon researchers have estimated that $\$ 211$ billion might be spent in revitalized Pittsburgh steel mills building Maglev trains. Even these figures pale when one considers the huge economic and environmental impact of replacing our currently

\section{The importance of} materials science to our general well-being and everyday quality of life should be obvious to all. But it seems that this is not so.

outmoded rail system with a new, rapid, efficient system.

Materials research will play a large role in the realization of this project because the technology is new and the choice of the ultimate system is not clear. Additionally, progress in normal and superconducting magnetic materials, materials for rail guides, and lightweight structural materials and composites for the trains will be required.

Maglev technology might be defined as a U.S. "cultural technology" because original patents for magnetic levitation are held by Dr. Gordon Danby and Dr. James Powell of Brookhaven National Laboratories. But we are in danger of losing the right to claim it as our cultural technology because companies in Japan, West Germany, and Great Britain have taken the lead. Japan is already proceeding to build a test track for a proposed $325 \mathrm{mph}$ "Supertrain" replacing the famous and economically successful "Bullet Train" linking Tokyo and Osaka. Carrying 10,000 passengers per hour, the "Supertrain" will cut the time between Tokyo and Osaka from three hours to one hour. It is expected to cost $\$ 25$ billion, primarily because of Japan's high land cost, but has already created a minor economic boom in Japan.

I ask each reader to compare a project like the Maglev project with a project like the SSC, both from the point of view of materials science and from the point of view of the national quality of life. I further ask each reader to think of other "banner projects" for materials science which will help us demonstrate to legislators and the public the value of material science. Then ask "why isn't this happening?"

R.R. Chianelli

\section{Attention MRS Members...}

Ballots for the election of three Officer and five Councillor positions have been mailed. Your ballot must be received by September 15, 1990 in order to be counted.

\section{Candidates for MRS Office and Council:}

First Vice President:

Slade Cargill, IBM T.J. Watson Research Center

Clifton W. Draper, AT\&T Bell Laboratories

\section{Second Vice President:}

Robert J. Nemanich, North Carolina State University

S. Thomas Picraux, Sandia National Laboratories

\section{Treasurer:}

Charles B. Duke, Xerox Research Laboratories

J. Francis Young, University of Illinois
Councillor:

John C. Bravman, Stanford University

Gregory C. Farrington, University of Pennsylvania

Robin F.C. Farrow, IBM Almaden Research Laboratory

D. Wayne Goodman, Texas A\&M University

Gary L. McVay, Battelle Pacific Northwest Laboratory

Gregory L. Olson, Hughes Research Laboratories

Paul S. Peercy, Sandia National Laboratories

Julia M. Phillips, AT\&T Bell Laboratories

Rustum Roy, Pennsylvania State University

Carl V. Thompson, Massachusetts Institute of Technology 